\title{
O ESTUDO SOBRE A FORMAÇÃO DO PROFESSOR DE LÍNGUA PORTUGUESA NO PARFOR LETRAS
}

\author{
Herodoto Ezequiel Fonseca da SILVA ${ }^{1}$ \\ Márcio Oliveiros Alves da SILVA²
}

\begin{abstract}
RESUMO: Temos como objetivo compreender o estado atual sobre as pesquisas que tomam como objeto a Formação dos Professores de Língua Portuguesa, no âmbito de cursos de Letras ofertados pelo PARFOR. Buscamos produções acadêmicas no banco de teses da Capes que investigavam essa temática. Selecionamos, também, as dissertações e teses produzidas no âmbito de Programas de Pós-Graduação do Estado do Pará. Fizemos a sistematização dessas monografias por meio das seguintes categorias: objeto de pesquisa, procedimentos metodológicos, filiação teórica para análise dos dados, o papel da escrita na formação do professor e a percepção da ação formativa oferecida pelo PARFOR. Constatamos a fecundidade da temática da formação de professores no PARFOR nas produções acadêmicas e a percepção dos pesquisadores ora com críticas ora com reconhecimento da relevância do Plano.
\end{abstract}

PALAVRAS-CHAVE: Formação do professor, PARFOR, Graduação em Letras.

ABSTRACT: We aim to understand the current state of research that takes as its object the Portuguese Language Teachers Education, within the scope of courses offered by PARFOR. We looked for academic productions in the thesis bank of Capes that have investigated this theme. We have selected the theses produced in the scope of Postgraduate Programs in the State of Pará. We have systematized these monographs through the following categories: object of research, methodological procedures, theoretical affiliation for data analysis, the written's role in the Teachers Education and the perception of the education offered by PARFOR. We note the fecundity of the teachers education in PARFOR in academic productions and the researchers' perception with criticism and in other moments recognition of relevance of the Plan.

KEYWORDS: Teacher Education, PARFOR, Letters Graduate.

\section{INTRODUÇÃO}

O texto esboça uma compreensão do estado atual sobre as pesquisas que tomam como objeto a Formação dos Professores de Língua Portuguesa, no âmbito de cursos de Letras ofertados pelo Plano Nacional de Formação de Professores da Educação Básica (doravante, PARFOR). Trata-se de um Plano de Formação de Professores em nível nacional que tem ofertado cursos de licenciatura e que, desde sua implantação, tornou-se objeto de estudo acadêmico em várias áreas do conhecimento.

O interesse por tal temática surgiu devido à nossa inserção, desde a implantação do PARFOR no Pará, como professores-formadores atuando nas mais variadas disciplinas do curso de Letras da UFPA. Em meio a vários momentos de ensino e olhar investigativo sobre nossa prática docente, fomos instados a buscar respostas aos seguintes questionamentos:

\footnotetext{
${ }^{1}$ Mestre em Letras pela Universidade Federal do Pará. Docente do Instituto Federal de Educação, Ciência e Tecnologia do Pará. Doutorando do PPGL-UFPA. E-mail: heroezq@yahoo.com.br.

2 Doutor em Educação pela Universidade Federal do Pará. Técnico Pedagógico do Conselho Estadual de Educação do Pará. E-mail: haybe28@yahoo.com.br.
} 


\section{$=$ TRAMA $=$}

Qual o estado atual sobre as pesquisas acadêmicas que se debruçaram sobre a formação de professores no âmbito do PARFOR? E, sendo mais específico: O que já foi dito sobre a formação de professores de Língua Portuguesa oferecida no âmbito do mesmo Plano?

Considerando essas questões, o objetivo deste estudo é discutir as pesquisas já desenvolvidas acerca da formação do professor de Língua Portuguesa em cursos de licenciatura em Letras ofertados no âmbito PARFOR ${ }^{3}$. O referido objetivo de estudo passa a ser trabalhado por etapas. A primeira etapa foi a de buscar as dissertações e teses no sítio eletrônico do Banco de Teses da Capes, o que resultou em um mapeamento quantitativo das produções acadêmicas acessadas. Em seguida, organizamos esses dados quantitativos obtidos de acordo com (1) o ano de defesa, (2) a área de conhecimento das investigações, (3) as Instituições de Ensino Superior (IES) em que as produções acadêmicas foram concebidas, (4) o nível acadêmico (se mestrado ou doutorado) e (5) os cursos de licenciatura investigados.

Após essa etapa, selecionamos as dissertações e teses que se debruçaram sobre a formação do professor de língua portuguesa no PARFOR Letras para analisarmos seus conteúdos e depreendermos as regularidades temáticas acerca do estado do conhecimento atual sobre o assunto. Trata-se de uma etapa primordial para reconhecer e definir o objeto "de tal maneira que seja reconhecível igualmente pelos outros" (ECO, 2012, p. 21). Tivemos que "escutar" o que já foi dito por meio da leitura atenta e responsável dos textos a partir da identificação das regularidades no que diz respeito mais especificamente aos seguintes itens: os objetos de pesquisa escolhidos, os procedimentos metodológicos utilizados, a filiação teórica assumida nas produções e o papel da escrita do aluno-professor para a sua formação. Só após este trabalho poderemos identificar os avanços já empreendidos sobre o referido objeto e, assumindo a natureza da linguagem como dialógica, polifônica, inconclusa, "dizer do objeto algo que ainda não foi dito ou rever sob uma óptica diferente o que já se disse" (ECO, 2012, p. 22) para que assim possamos contribuir para o avanço teórico e prático do campo da formação do professor de língua portuguesa como língua materna e seu ensino.

De acordo com os critérios de classificação dos tipos de pesquisa científica de Tognetti (2006 apud RAMOS, 2009, p. 182), este estudo é uma pesquisa básica, já que a questão aqui levantada é de ordem intelectual, visando à ampliação do saber acerca da formação oferecida pelo PARFOR e especificamente pelo PARFOR Letras. Quanto ao objetivo, trata-se de uma pesquisa exploratória, pois se faz um estudo para ganhar maior familiaridade com o problema de pesquisa - a formação do professor de Língua Portuguesa (ou apenas "LP") no contexto do PARFOR. Quanto aos procedimentos, caracteriza-se como uma pesquisa bibliográfica uma vez que discutimos o conjunto de conhecimentos já produzidos acerca da formação do professor de LP no contexto do PARFOR, em produções acadêmicas (dissertações e teses). Nosso estudo é de natureza, predominantemente, qualitativa onde fazemos a discussão do conteúdo apresentado nas monografias.

$\mathrm{Na}$ continuação deste artigo, desenvolvemos o levantamento das produções acadêmicas acessadas no Banco de Teses da Capes e, posteriormente, discutimos o conteúdo das monografias que tratam exclusivamente de pesquisas sobre a formação do professor de Língua Portuguesa no contexto de cursos de Letras do PARFOR. Na última seção, apresentamos as considerações finais do estudo.

\footnotetext{
${ }^{3}$ Houve a necessidade de fazer este estudo uma vez que os sujeitos de nossas pesquisas em nível de doutorado são professores da Educação Básica atendidos pelo curso de licenciatura em Letras do PARFOR/UFPA.
} 


\section{$=\mathrm{T} R A M A=$}

\section{O PANORAMA DA PRODUÇÃO ACADÊMICA SOBRE O PARFOR}

Neste momento passamos pelo entendimento do Plano Nacional de Formação de Professores da Educação Básica e das pesquisas acadêmicas sobre o atinente Plano. $O$ PARFOR foi instituído por meio do Decreto No 6.755, 29 de janeiro de 2009 (BRASIL, 2009), que instaurou a Política Nacional de Formação de Profissionais do Magistério da Educação Básica, cuja principal finalidade foi a de "organizar, em regime de colaboração entre a União, os Estados, o Distrito federal e os Municípios, a formação inicial e continuada dos profissionais do magistério para as redes públicas da Educação Básica". (BRASIL, 2009).

Essa política foi concebida principalmente para sanar os desajustes da formação dos professores exigida no Brasil desde a Lei de Diretrizes e Bases da Educação Nacional, de 1996, onde prescrevia que para os professores atuarem nos níveis da educação básica (ensino fundamental e médio) estes precisariam ser formados em curso superiores de licenciatura em instituições autorizadas e reconhecidas pelo MEC. Então, o PARFOR surgiu neste cenário de exigência de adequação - já bem atrasada - à legislação educacional vigente. $O$ atraso nessa adequação formativa fez com que o Plano fosse concebido como uma política emergencial o que acarretou na forte intensificação e necessidade de rapidez nas ações administrativas, pedagógicas e curriculares para o início da implementação das ações formativas.

Fazendo a busca no sítio eletrônico do Banco de Teses e Dissertações da CAPES ${ }^{4}$ a partir do termo "PARFOR", obtivemos como resultado 97 produções acadêmicas. Destas 97 produções, 22 datam de 2016, 32 de 2015, 21 de 2014, 19 de 2013 e 3 de 2012. Para melhor visualização, vejamos a tabela abaixo:

Tabela 1 - Ano de defesa

\begin{tabular}{cc}
\hline Ano de defesa & Quantidade \\
\hline 2012 & 3 \\
\hline 2013 & 19 \\
\hline 2014 & 21 \\
\hline 2015 & 32 \\
\hline 2016 & 22 \\
\hline Total & 97 \\
\hline
\end{tabular}

Fonte: Banco de Teses da Capes.

Ao considerar esses dados retirados do repositório do banco de teses e dissertações da CAPES, nota-se que a produção acadêmica no país a respeito do PARFOR inicia no ano de 2012, possivelmente pelo fato de ele ter iniciado legalmente no ano de 2009 (Decreto $n^{\circ}$ 6.755/2009). Além disso, a execução do plano por meio das ações formativas provavelmente teria sido iniciada em 2010, o que foi o caso da UFPA quando as primeiras turmas iniciaram devido ao registro do ano de construção do Projeto Pedagógico de Curso (PPC) do PARFOR Letras da UFPA (2010) e a resolução que aprovava o referido curso (2011). Mas, mesmo com esse curto tempo de existência do programa, percebe-se a fecundidade do assunto por já ter um total de 97 produções acadêmicas em um intervalo de tempo de 5 anos (de 2012 a 2016). Um exemplo do salto quantitativo na produção é o caso da diferença de textos defendidos entre o ano de 2012 e o de 2013, isto é, de 3 produções defendidas, aumentando para 19.

No que diz respeito à área de conhecimento ${ }^{5}, 71$ são da área de Educação, 10 de Ensino de Ciências e Matemática, 3 de Letras, 3 de Sociais e Humanidades, 2 de Linguística, 2

\footnotetext{
${ }^{4}$ Disponível em: www.bancodeteses.capes.gov.br . Acesso em 28 fev. 2017.

5 Estas áreas de conhecimento são as mesmas disponibilizadas no banco de dados da CAPES e a partir das quais são organizadas as produções acadêmicas no sítio eletrônico do banco de teses e dissertações da referida Coordenação de
} 


\section{$=$ TRAMA $=$}

de Ensino, 1 de Administração Pública, 1 de Ciência da Computação, 1 de Educação de Jovens e Adultos, 1 de Música, 1 de Tecnologia Educacional e 1 de Interdisciplinar.

Tabela 2 - Área de Conhecimento

\begin{tabular}{cc}
\hline Área de conhecimento & Quantidade \\
\hline Educação & 71 \\
\hline Ensino de Ciências e Matemática & 10 \\
\hline Letras & 3 \\
\hline Sociais e Humanidades & 3 \\
\hline Linguística & 2 \\
\hline Ensino & 2 \\
\hline Administração Pública & 1 \\
\hline Ciência da Computação & 1 \\
\hline Educação de Jovens e Adultos & 1 \\
\hline Música & 1 \\
\hline Tecnologia Educacional & 1 \\
\hline Interdisciplinar & 1 \\
\hline Total & 97
\end{tabular}

A partir desta tabela, constata-se que a área de conhecimento de Educação apresenta maior produtividade a respeito do PARFOR no país com 71 produções de um total de 97. Por se tratar de uma política pública no campo educacional, obviamente os Programas de PósGraduação em Educação no País voltam suas atenções para tal ação do Estado e também pelo fato de os cursos de Pedagogia serem os de maior número de turmas ofertadas. Soma-se a isso o fato de em vários desses programas de pós-graduação existir linhas de pesquisa que se debruçam sobre as políticas educacionais. Chama-nos a atenção também o fato de na área de Letras constar apenas 3 produções e na área de Linguística apenas 2, o que sinaliza uma fronteira a se expandir com pesquisas e produções acadêmicas nos Programas de PósGraduação de Letras e de Linguística para a análise das práticas de linguagem que povoam o cotidiano das atividades administrativas e de ensino do PARFOR, o processo de ensinoaprendizagem da língua portuguesa e o processo de formação de professores de língua portuguesa discutidos na licenciatura em Letras. Esse aspecto do pequeno número de textos produzidos em Programas de Pós-Graduação em Letras e Linguística sobre a referida temática igualmente justifica a necessidade de se empreender mais investigação nessas áreas fim de contribuir para a reflexão da formação do professor de língua.

Quanto à Instituição, 11 produções acadêmicas foram elaboradas no âmbito da Universidade Federal da Bahia, 9 da Universidade Federal do Pará, 6 da Universidade Católica de Santos, 4 da Universidade Estadual do Sudoeste da Bahia, 3 da Universidade do Estado do Pará, 2 da Fundação Universidade Federal de Mato Grosso do Sul, 2 da Fundação Universidade Federal do Piauí, 2 da Pontifícia Universidade Católica de Goiás, 2 da Universidade Comunitária da Região de Chapecó, 2 da Universidade do Estado da Bahia, 2 da Universidade Estadual de Feira de Santana, 2 da Universidade Estadual de Maringá e 2 da Universidade Estadual do Norte Fluminense Darcy Ribeiro ${ }^{6}$.

Aperfeiçoamento. Preferimos utilizar as "áreas de concentração" às outras formas de filtrar a busca no site, pois com elas teríamos acesso a dados filtrados de forma um pouco mais detalhada.

${ }^{6}$ As demais produções acadêmicas foram elaboradas em outras Instituições de Ensino Superior, cada uma com uma produção acadêmica. 


\section{$=\mathrm{TRAMA}=$}

Tabela 3 - Instituições

\begin{tabular}{|c|c|}
\hline Instituições & Quantidade \\
\hline Universidade Federal da Bahia & 11 \\
\hline Universidade Federal do Pará & 9 \\
\hline Universidade Católica de Santos & 6 \\
\hline $\begin{array}{l}\text { Universidade Estadual do } \\
\text { Sudoeste da Bahia }\end{array}$ & 4 \\
\hline Universidade do Estado do Pará & 3 \\
\hline $\begin{array}{c}\text { Fundação Universidade Federal } \\
\text { de Mato Grosso do Sul }\end{array}$ & 2 \\
\hline $\begin{array}{c}\text { Fundação Universidade Federal } \\
\text { do Piauí }\end{array}$ & 2 \\
\hline $\begin{array}{c}\text { Pontifícia Universidade Católica } \\
\text { de Goiás }\end{array}$ & 2 \\
\hline $\begin{array}{l}\text { Universidade Comunitária da } \\
\text { Região de Chapecó }\end{array}$ & 2 \\
\hline Universidade do Estado da Bahia & 2 \\
\hline $\begin{array}{l}\text { Universidade Estadual de Feira de } \\
\text { Santana }\end{array}$ & 2 \\
\hline Universidade Estadual de Maringá & 2 \\
\hline $\begin{array}{l}\text { Universidade Estadual do Norte } \\
\text { Fluminense Darcy Ribeiro }\end{array}$ & 2 \\
\hline Outras IES ${ }^{7}$ & 48 \\
\hline Total & 97 \\
\hline
\end{tabular}

No que diz respeito às Instituições, a UFBA detém o primeiro lugar no quantitativo de produções acadêmicas a respeito do PARFOR com 11 produções; em segundo lugar, aparece a UFPA com 9 produções. Percebe-se ainda a participação da UEPA com 3 produções, o que mostra a atenção das universidades públicas também do Pará para este programa. Entendemos que uma das justificativas para estes dados seria o fato de as regiões Norte e Nordeste terem sido as que mais possuíam alunos-professores atendidos pelo PARFOR em 2014, tal como se pode perceber no gráfico 1 a seguir:

Gráfico 1 - Quantidade de alunos-professores cursando o PARFOR em 2014 por região do Brasil

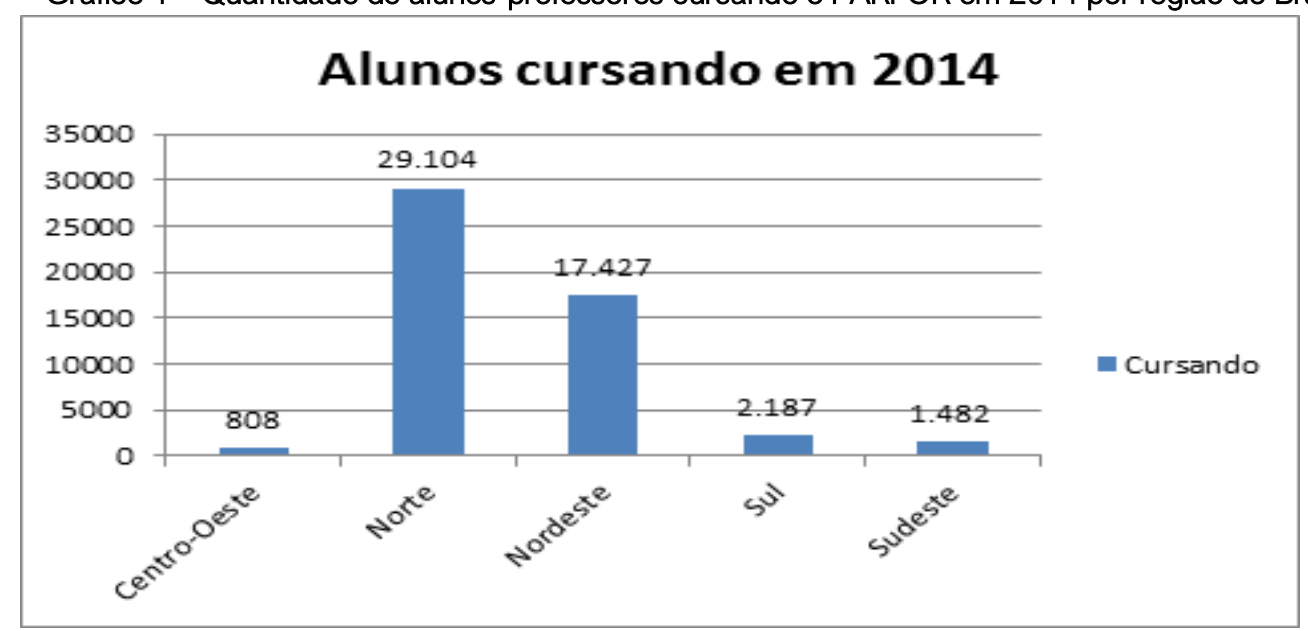

Fonte: Disponível em: http://www.capes.gov.br/educacao-basica/parfor. Acesso em 19 set. 2016.

${ }^{7}$ Cada uma dessas outras IES possui uma produção. A fim de se ter uma visão daquelas instituições mais ativas na produção acadêmica relacionada ao PARFOR e para que a tabela não ficasse muito extensa, apresentamos apenas o total dessas outras produções em outras instituições. 
Como podemos perceber, na região Norte, eram 29.104 alunos-professores participando dos cursos ofertados pelo PARFOR e na região Nordeste eram 17.427. Esse dado nos leva a supor que grande foi o repasse de verbas públicas para garantir o funcionamento de todo este quantitativo de turmas nas regiões citadas, fazendo com que as pesquisas em nível de pós-graduação também investigassem, resumida e diretamente, a qualidade da formação oferecida para estes graduandos em face de todo o investimento dispensado.

A fim de discutir o conteúdo das produções acadêmicas, do universo de 97 produções como foi dito mais acima, fizemos as seguintes escolhas metodológicas: primeiramente, selecionamos as dissertações e teses inseridas nas áreas de conhecimento "Letras" e "Linguística" que totalizam 5 produções e, em seguida, selecionamos as dissertações e teses produzidas em Programas de Pós-Graduação de IES públicas do Estado do Pará, ou seja, da UFPA e da UEPA, que totalizam 12 produções. Logo abaixo, segue a tabela com essas informações numéricas:

Tabela 4 - Quantitativo das produções acadêmicas quanto às áreas de concentração, às IES públicas do Pará em que foram concebidas e ao nível acadêmico da pesquisa

\begin{tabular}{|c|c|c|c|}
\hline $\begin{array}{c}\text { Área de } \\
\text { Conhecimento }\end{array}$ & $\begin{array}{l}\text { Produções } \\
\text { acadêmicas }\end{array}$ & Nível acadêmico & Total \\
\hline \multirow[t]{2}{*}{ "Letras" } & 3 & Mestrado & 3 \\
\hline & & Doutorado & 0 \\
\hline \multirow[t]{2}{*}{ "Linguística" } & 2 & Mestrado & 1 \\
\hline & & Doutorado & 1 \\
\hline Total & & & 5 \\
\hline Instituição & $\begin{array}{l}\text { Produções } \\
\text { acadêmicas }\end{array}$ & Nível acadêmico & Total \\
\hline \multirow[t]{2}{*}{ UFPA } & 9 & Mestrado & 5 \\
\hline & & Doutorado & 4 \\
\hline \multirow[t]{2}{*}{ UEPA } & 3 & Mestrado & 3 \\
\hline & & Doutorado & 0 \\
\hline Total & & & 12 \\
\hline Total de produções & & & \\
\hline acadêmicas & & & 17 \\
\hline
\end{tabular}

A seleção de acordo com esses dois grupos (área de conhecimento e IES) teve por objetivo verificar o estado atual da produção do conhecimento acerca deste programa educacional nacionalmente e no Estado do Pará. Fizemos a leitura das 17 produções acadêmicas, orientados a partir dos seguintes itens: referência completa, objetivos da pesquisa, pergunta de pesquisa, objeto de pesquisa, procedimentos metodológicos, filiação teórica para a análise dos dados, resultados alcançados e o papel da escrita do graduando na pesquisa. Com as informações obtidas com esses itens norteadores, produzimos um quadro sinóptico em programa eletrônico de edição de texto, que, por sua vez, possibilitou identificarmos as produções acadêmicas que pesquisaram a formação do professor de língua portuguesa em cursos de licenciatura em Letras ofertados pelo PARFOR: 3 monografias (duas dissertações e uma tese). Dentre as áreas de formação que foram objeto de investigação nos textos lidos, percebemos a seguinte configuração quantitativa: 


\section{$=\mathrm{T} R A M A=$}

Tabela 5 - Quantitativo das produções acadêmicas quanto às áreas de formação investigadas

\begin{tabular}{lc}
\hline $\begin{array}{l}\text { Áreas de formação } \\
\text { investigadas }\end{array}$ & Quantidade \\
\hline Pedagogia & 7 \\
\hline Letras - Português & 3 \\
\hline Letras - Inglês & 3 \\
\hline Educação Física & 1 \\
\hline $\begin{array}{l}\text { Não há estudo de um } \\
\text { curso específico }\end{array}$ & 3 \\
\hline \multicolumn{2}{c}{ Total } \\
\hline \multicolumn{2}{c}{ Fonte: Produto da pesquisa. }
\end{tabular}

Com a tabela 5 acima, nota-se um total de apenas 3 produções acadêmicas que investigam a formação do professor de português em curso de Letras - Língua portuguesa pelo PARFOR. Isso demonstra que, mesmo em um universo de 97 produções acadêmicas que investigaram ações do PARFOR no Brasil entre os anos de 2012 e 2016 e mesmo com a grande quantidade de professores de português egressos de tais cursos, a formação de professores de LP em cursos de Letras no âmbito PARFOR até agora foi pouco estudada.

A partir dos dados apresentados nas tabelas acima, pudemos perceber que (1) o PARFOR demonstrou fecundidade para as pesquisas acadêmicas em nível de pós-graduações em curto espaço de tempo no Brasil; (2) a produtividade da área da Educação nas pesquisas sobre a formação de professores no contexto do PARFOR; (3) o destaque das IEs do Nordeste e do Norte na produtividade das pesquisas, demonstrando reciprocidade com a quantidade de alunos matriculados no PARFOR nessas regiões; (4) o quantitativo pequeno de produções da área de Letras e Linguística e menor ainda o quantitativo de monografias em nível de doutorado; e (5) a timidez no quantitativo de produções sobre o PARFOR que tratam da formação do professor de língua portuguesa em cursos de Letras - Português.

Passemos, neste momento, para o estudo das dissertações e teses produzidas no Brasil cujo interesse de pesquisa foi a formação de professores de Língua Portuguesa oferecida no âmbito do PARFOR.

\section{O QUE JÁ FOI DITO SOBRE A FORMAÇÃO DE PROFESSORES DE LP DO PARFOR-LETRAS}

Nesta seção, atentar-nos-emos de forma mais específica nos dados fornecidos por meio da leitura dos textos das dissertações e teses acessadas cujo objeto de pesquisa foi a formação de professores de português no PARFOR. Primeiramente, apresentamos as referências completas das produções e depois discorremos sobre cada uma delas.

O Quadro 1, a seguir, apresenta as referências das produções acadêmicas que investigaram a formação do professor de língua portuguesa em cursos de Letras - Português ofertados pelo PARFOR, organizadas em ordem cronológica em relação ao ano de defesa.

Quadro 1 - Referências das produções acadêmicas que investigaram a formação do professor de língua portuguesa em cursos de Letras - Português ofertados pelo PARFOR

ATAIDE, Denyse Mota da Silva. Letramento digital e formação de professores: Limites e potencialidade na perspectiva do Plano Nacional de Formação de professores (PARFOR). Dissertação (Mestrado). Programa de Pós-Graduação em Letras, Universidade Federal do Tocantins, Araguaína, 2013.

VALENTE, Luiz de Nazaré Viana. A formação de professores de português em serviço: repercussões e elementos contraditórios. Dissertação (Mestrado). Programa de Pós-Graduação em Educação, Universidade Federal do Pará, Belém, 2015. 
SILVA, Márcio Oliveiros Alves da. A ressignificação da prática de leitura dos graduandos do Curso de

Letras PARFOR - UFPA: Território de Formação, Subjuntividade e Horizonte Social do Leitor. Tese

(Doutorado). Programa de Pós-Graduação em Educação, Universidade Federal do Pará, Belém, 2016.

\section{Fonte: Produto da pesquisa.}

A partir destes dados, faremos a discussão desses três textos de acordo com as seguintes categorias: (i) os objetos de pesquisa escolhidos, (ii) os procedimentos metodológicos utilizados, (iii) a filiação teórica assumida nas produções e (iv) o papel da escrita ${ }^{8}$ do graduando para a sua formação; e (v) a percepção da ação formativa oferecida pelo PARFOR.

\section{A DISSERTAÇÃO “LETRAMENTO DIGITAL E FORMAÇÃO DE PROFESSORES”}

No que se refere ao objeto de pesquisa escolhido, Ataide (2015) - dissertação produzida no Programa de Pós-Graduação em Letras da Universidade Federal de Tocantins investiga as práticas de letramento digital (mais especificamente o computacional) e a formação continuada de professores no Curso de Letras do PARFOR da UFT de Araguaina. A dissertação teve como objetivo identificar, descrever e analisar as práticas de letramento digital, tendo como foco o Curso de Letras do PARFOR, alcançando professores formadores e em formação, avaliando suas interações na construção do conhecimento, mediados pelo computador e seus artefatos. Segundo a autora, o método escolhido foi o da Fenomenologia e a pesquisa foi denominada de "quantiqualitativa".

As técnicas de coleta de dados foram a pesquisa bibliográfica e documental, estudo de caso, observação em duas turmas do referido curso, entrevistas semiestruturadas e aplicação de questionários. Essa investigação filiou-se, teoricamente, aos estudos do Letramento e do Letramento Digital em interface com os estudos sobre a Formação de Professores. Quanto ao papel da escrita do graduando para a sua formação, visualizando a lista dos instrumentos para coleta de dados (ATAIDE, 2013, p. 60), percebemos que a escrita do graduando de Letras é mobilizada nas respostas ao questionário para coletar as informações sobre o perfil socioeconômico, a formação, a experiência profissional e a prática docente dos graduandos. A fim de investigar as práticas de letramento Digital dos alunos-professores ao utilizarem o Ambiente Virtual de Aprendizagem em atividades de disciplinas a distância, a pesquisadora analisa excertos de interações escritas dos graduandos em emails, fóruns virtuais e chats no moodle ${ }^{9}$, onde respondem a questões do professor-formador e apresentam suas dúvidas e comentários a respeito do conteúdo estudado.

No que diz respeito à ação formativa oferecida pelo PARFOR, a autora enuncia o seguinte em seu capítulo de considerações finais:

No que diz respeito ao curso de PARFOR de Letras, aqui estudado, percebemos que o fato de o mesmo não ter um Projeto Pedagógico que direcione as ações do curso, conforme constatamos, é um problema, pois, ao ser regido pelo Projeto Pedagógico do Curso Presencial, muitas lacunas se revelam, uma vez que os procedimentos pedagógicos de um curso na modalidade semipresencial são, em muitos aspectos, diferentes do curso presencial.

Entretanto, e apesar do PARFOR ser uma modalidade de curso com uma vasta legislação que o sustenta, em nossa pesquisa não identificamos nenhuma alusão ao fato de as Instituições efetivarem

\footnotetext{
${ }^{8}$ Assim como Fiad e Silva (2009), Fairchild (2010) e Silva (2012), também consideramos o lugar de destaque da escrita no processo de formação docente, pois é na e pela escrita que o sujeito em formação pode registrar as práticas de ensino vivenciadas - aqui, referimo-nos principalmente a disciplinas como estágio supervisionado -, refletir sobre essas práticas e refletir sobre seu processo de constituição de sujeito como profissional docente. Por conta disso é que buscamos perceber o papel da escrita do graduando em sua formação.

9 Trata-se de uma plataforma na internet utilizada para hospedar cursos a distância online.
} 


\section{$=$ TRAMA $=$}

um Projeto exclusivo para as ações do curso. E isso é um fator que colabora para que existam algumas lacunas na efetivação dos procedimentos pedagógicos e didáticos. (ATAIDE, 2013, p. 141-142)

Em tom de crítica, a autora negocia os sentidos referentes à formação oferecida pelo PARFOR Letras da UFT como sendo problemática devido à ausência de orientações específicas às atividades didático-pedagógicas a distância do curso, pelo fato de na referida instituição o curso do PARFOR ter admitido o PPC do curso de Letras presencial. Ou seja, a autora denuncia a inadequação do PPC utilizado pelo curso do PARFOR o que ocasionou ausência de orientação oficial quanto às atividades a distância e por consequência prejudicou o processo de letramento digital por parte dos alunos-professores.

Na continuação da citação, por meio de uma estrutura sintática marcada pelo operador argumentativo que orienta para conclusões contrárias apesar de, a autora sinaliza a contradição de o PARFOR ter uma vasta legislação, no entanto nesta mesma legislação não se faz referência explícita à necessidade de elaboração de um projeto pedagógico específico para os cursos ofertados no contexto do Plano de Formação. Por meio da relação lógica de causa e efeito, a autora pontua as lacunas geradas no processo formativo dos alunos-professores atendidos pelo PARFOR, principalmente no que diz respeito ao desenvolvimento das habilidades de letramento digital pelos sujeitos de sua pesquisa.

\section{A DISSERTAÇÃO “A FORMAÇÃO DE PROFESSORES DE PORTUGUÊS EM SERVIÇO”}

A dissertação de Valente (2015), elaborada no Programa de Pós-Graduação em Educação da Universidade Federal do Pará, demonstra como objeto de pesquisa "a formação docente do professor de Português, oferecida pelo PARFOR, a partir da ótica dos próprios egressos." (p. 16). Segundo o autor, o objetivo do trabalho foi o de descrever e analisar as especificidades, repercussão e elementos contraditórios do PARFOR a partir da visão dos egressos de uma turma do Curso de Letras - Português, no município de Cametá-PA e do Projeto Pedagógico desse Curso (p. 18).

Os procedimentos metodológicos foram os listados: a composição do corpus se deu por meio de "documentos e depoimentos de egressos, gerados a partir de entrevistas semiestruturadas, tendo com [sic] alvo a primeira turma de LETRAS (Habilitação Língua Portuguesa), formada pelo programa no município de Cametá-PA" (p. 7). O procedimento de interpretação dos dados se deu nos moldes da Análise de Conteúdo; o Método foi o histórico dialético. O pesquisador utilizou o gravador para coletar as entrevistas. A análise dos dados ocorreu seguindo categorias analíticas próprias do materialismo histórico-dialético, a saber, da "totalidade", "história" e "contradição" e categorias empíricas da "formação", "qualificação" e "valorização". A filiação teórica foi estabelecida nessas categorias centrais já mencionadas do materialismo histórico-dialético. Pelo fato de o instrumento de coleta e de geração do corpus da pesquisa ter acontecido por meio de entrevista, cujo registro das informações fornecidas pelo sujeito acontece pela modalidade oral da língua, a escrita do graduando do PARFOR não foi investigada. Isso se constata ao estudarmos o capítulo de análise da dissertação, onde Valente (2015) analisa trechos das falas dos alunos-professores que apresentam suas opiniões a respeito das ações formativas vivenciadas durante o curso do PARFOR e as repercussões em sua formação como egressos do curso.

O trecho abaixo retirado da seção de conclusão da dissertação de Valente (2015) demonstra a imagem de formação docente ofertada pelo PARFOR:

Em suma, os elementos contraditórios da formação de professores de português em serviço, do programa PARFOR emergem da própria lógica gerencialista do Estado pós 90, que baseada na 


\section{$=$ TRAMA $=$}

formação voltada para eficiência, eficácia e com menos custo idealizou, concebeu e implementou políticas públicas educacionais de maneira unilateral, o que, de certa forma, além de culminar no aligeiramento de implementação e consequentemente falta de estrutura e diálogo mais profícuo com os parceiros operacionais como IES e prefeituras, acabou contribuindo para a elaboração de um currículo sem a devida tematização e amadurecimento para realidades específicas e locais. (...) Contudo não podemos deixar de reconhecer da importância do PARFOR na vida de nossos professores que há anos vem sonhando com uma formação superior no interior da Amazônia (VALENTE, 2015, p. 97-98).

Sustentando sua argumentação na relação do PARFOR com a "lógica gerencialista do Estado pós 90", o autor apresenta sua crítica em relação à forma "aligeirada" como o plano foi implementado o que, segundo ao autor, resultou na elaboração de currículos sem a devida atenção às variáveis que precisam ser consideradas na concepção de projetos pedagógicos, tais como, o perfil do público alvo, as bases pedagógicas e teóricas, a realidade local onde acontece o curso de formação.

Na parte final do excerto, contrariamente à sua crítica ao plano, demarcada pelo uso do operador argumentativo contudo, o autor argumenta pela importância do PARFOR no processo de formação profissional docente em nível superior na vida dos alunos-professores. O pesquisador chegou a esta conclusão devido à análise dos relatos dos alunos-professores coletados. Valente, portanto, negocia os sentidos da ação formativa por dois caminhos argumentativos, a saber, o da crítica da concepção e implantação do plano e o da importância do plano na vida subjetiva e profissional dos professores atendidos pelo PARFOR.

\section{A TESE "A RESSIGNIFICAÇÃO DA PRÁTICA DE LEITURA DOS GRADUANDOS DO CURSO DE LETRAS PARFOR - UFPA"}

No caso da Tese de doutoramento de Silva (2016), o objeto investigado foi a Rede de Significado sobre as Lições de Leitura na experiência do Graduando no Curso de Licenciatura em Letras - PARFOR/UFPA e o objetivo geral foi o de "compreender a ressignificação dos discursos manifestados pelos Graduandos da Licenciatura em Letras para configurar uma Rede de Significado sobre as Lições de Leitura na experiência de Leitora" (p. 36).

A metodologia empregada foi, predominantemente, qualitativa e constituiu como locus de pesquisa uma turma do Curso de Letras - Português do município de Redenção/PA, e os instrumentos para coleta de dados foram 26 questionários, 09 entrevistas com caráter narrativo e 26 memoriais escritos pelos graduandos, juntamente com anotações em diário de campo do pesquisador.

No que diz respeito ao referencial teórico mobilizado na Tese, Silva (2016) lançou mão das seguintes noções teóricas: Rede de Significados, Dialogismo, Território de formação, Subjuntividade, Horizonte social do leitor, e as lições de leitura do sujeito. As noções teóricas possibilitaram a circunscrição do objeto de análise, a Rede de Significado acerca das Lições de Leitura no Curso de Letras - Português do graduando do PARFOR/UFPA. O objeto de análise possibilitou a investigação do:

O ambiente de sala de aula do Curso de Letras PARFOR/UFPA, no município de Redenção, permitiu o encontro entre as memórias das Lições de Leituras entre os Alunos do proferido Curso e o Professor, como o pesquisador desta Tese. (...)

O Território de Formação do Curso de Letras marca o encontro das experiências de si (PASSEGGI, 2011) é construído por meio da interpelação das mediações discursivas dos objetos de leituras na vida de cada Leitor. A cada novo diálogo na Turma do Curso de Letras trouxe um processo de ressignificação da historicidade das aprendizagens dos Graduandos e do Professor, pesquisador desta Tese. (SILVA, 2016, p. 200-201) 


\section{$=$ TRAMA $=$}

Como pode se perceber, a sala de aula foi o território da ação formativa concreta do desenvolvimento do Curso de Letras - habilitação em Língua Portuguesa do PARFOR/UFPA entre o grupo dos graduandos e o Professor da disciplina do atinente Curso, em que se manifestaram a cada disciplina um fórum de negociação dos significados atribuídos a partir dos objetos de leitura (os textos estudados no curso). Segundo o Silva (2016), esse fórum de negociação dos significados promoveu um encontro entre as memórias dos sujeitos, capazes de revelar uma compreensão da ação formativa por meio dos seguintes aspectos: a) a narrativa autobiográfica das lições de leitura dos graduandos expressa os valores, as passagens e as pessoas que marcam a singularidade e orientação das escolhas feitas durante o percurso formativo; b) o método autobiográfico acerca das Lições de Leitura no Território da Ação Formativa no Curso de Letras a partir de um olhar de um sujeito historicamente situado, o qual está inserido em um contexto de Formação de Adultos; e c) o sujeito em formação no Curso de Letras foi capaz de assumir a responsabilidade de compreender as Lições de Leitura, em cada disciplina, e operar, a um nível subjetivo, os mecanismos que o levam à chamada autoformação (com sentido de descoberta e de compreensão do significado atribuído ao conjunto de atividades por meio do texto acadêmico no Curso de Letras).

\section{CONSIDERAÇÕES FINAIS}

Neste trabalho, esboçamos o nosso trabalho de compreensão do estado atual sobre as pesquisas que tomam como objeto a Formação dos Professores de Língua Portuguesa, no âmbito de cursos de Letras ofertados pelo PARFOR. O que nos norteou foram os questionamentos feitos na introdução: Qual o estado atual sobre as pesquisas acadêmicas que se debruçaram sobre a formação de professores no âmbito do PARFOR? E, ainda: O que já foi dito sobre a formação de professores de Língua Portuguesa no âmbito do mesmo Plano?

Respondendo ao primeiro questionamento, constatamos que o PARFOR demonstrou fecundidade para as pesquisas em nível de pós-graduações em curto espaço de tempo no Brasil, predominantemente das pesquisas da área da Educação. As IEs do Nordeste e do Norte demonstram destaque na produtividade das pesquisas. As áreas de Letras e Linguística constituem pequena produtividade nas pesquisas que tratavam da formação de professores no âmbito do PARFOR e menor ainda o quantitativo de monografias em nível de doutorado.

Conclui-se com isso que é diminuta a quantidade de pesquisas empreendidas no país, de 2012 a 2016, que investiguem a formação do professor de LP no âmbito do PARFOR, demonstrando que, em um total de 97 produções que tratam sobre esse Plano Nacional, apenas 3 trabalhos tocam nesta área de atuação. Como consequência, o ensino de língua portuguesa passa a ser pouco discutido, uma vez que a abordagem do processo formativo do professor leva à reflexão - nem que seja mínima - também do ensino da língua que é o que acontece com as três produções acima descritas.

Quanto aos objetos de investigação, verifica-se a recorrência do processo formativo dos professores, perpassando por perspectivas diferentes para se compreender esse objeto principal, como por exemplo, a formação docente ora pelo Letramento e Letramento Digital, ora por depoimento de egressos e ainda pela Rede de Significado sobre as Lições de Leitura na experiência do Graduando para a sua constituição de sujeito histórico.

Quanto aos aspectos metodológicos, percebemos a recorrência da abordagem qualitativa no desenvolvimento das pesquisas, com a utilização de técnicas para coleta de dados recorrentes, a saber, a entrevista semiestruturada, o questionário e as anotações em diários de campo. Em Silva (2016), encontramos, diferentemente, a utilização de um instrumento por meio do qual foi possível coletar uma escrita mais reflexiva do graduando para 


\section{$=$ TRAMA $=$}

discutir aspectos discursivos da constituição dos sujeitos que foi o memorial docente, a partir da tarefa de "escrever uma narrativa acerca da trajetória das Práticas de Leituras na Formação Docente" (p. 45).

Teoricamente, os três trabalhos investigativos filiam-se em estudos ancorados em um viés sócio-histórico-cultural, caminhando pelas noções de Dialogismo, Horizonte Social, Letramento, ora posicionados nestas três áreas maiores: Linguística, Educação, Psicologia Cultural e os Estudos Culturais.

Consoante ao papel da escrita do aluno-professor no processo investigativo, as dissertações pouco fazem essa incursão, já que apenas Ataide (2013) faz uso de questionário para graduandos responderem e depois trabalhar analiticamente sobre esses dados e sobre excertos de interações escritas dos graduandos em emails, fóruns virtuais e chats no moodle. Já na tese estudada, percebemos o trabalho com uma escrita mais reflexiva do aluno-professor no processo de análise dos dados, para se perceber, na escrita de si, a rede significados por meio das experiências de leitura dos graduandos.

\section{REFERÊNCIAS}

ATAIDE, D. M. S. Letramento digital e formação de professores: Limites e potencialidade na perspectiva do Plano Nacional de Formação de professores (PARFOR). Dissertação (Mestrado). Programa de Pós-Graduação em Letras, Universidade Federal do Tocantins, Araguaína, 2013.

BRASIL. Decreto n 6.755, de 29 de janeiro de 2009. Institui a Política Nacional de Formação de Profissionais do Magistério da Educação Básica. Brasília, DF, 29 jan. 2009. Disponível em: http://www.planalto.gov.br/ccivil 03/ ato2007-2010/2009/decreto/d6755.htm. Acesso em: 22 dez. 2016.

ECO, U. A escolha do tema. In:__. Como se faz uma tese. Trad. Gilson Cesar Cardoso de Souza. 24. ed. São Paulo: Perspectiva, 2012, p. 7-34.

FAIRCHILD, T. M. O professor no espelho: refletindo sobre a leitura de um relatório de estágio na graduação em Letras. In: Revista Brasileira de Linguística Aplicada. Belo Horizonte: UFMG/ALAB. v. 10, n. 1, 2010, p. 271288.

FIAD, R. S.; SILVA, L. L. M. Escrita na formação docente: relatos de estágio. In: Acta Scientiarum. Language and Culture. Maringa: EDUEM. v. 31, n. 2, 2009, p. 123-131.

RAMOS, A. Competências: a pesquisa como meio de conhecimento e transformação. In:

Metodologia da pesquisa científica: como uma monografia pode abrir o horizonte do conhecimento. São Paulo: Atlas, 2009, p. 169-195.

SILVA, M. O. A. A ressignificação da prática de leitura dos graduandos do Curso de Letras PARFOR - UFPA: Território de Formação, Subjuntividade e Horizonte Social do Leitor. Tese (Doutorado). Programa de PósGraduação em Educação, Universidade Federal do Pará, Belém, 2016.

SILVA, W. R. Proposta de análise textual-discursiva do gênero relatório de estágio supervisionado. In: D.E.L.T.A., 28:2, 2012, p. 281-305.

VALENTE, L. N. V. A formação de professores de português em serviço: repercussões e elementos contraditórios. Dissertação (Mestrado). Programa de Pós-Graduação em Educação, Universidade Federal do Pará, Belém, 2015. 